\title{
The Concentration-Profitability Relationship in Turkish Industry
}

\author{
Meral Ozhan \\ Hacettepe University \\ Ankara, Türkiye
}

\begin{abstract}
The concept of industrial concentration refers to the control of a given industry by a small number of leading firms which are exclusively engaged in that industry. In economic theory concentration is an important concept to understand a departure away from competitive market structure which is accepted as a reference point for efficiency. Using the traditional structureconduct-performance (SCP) paradigm many researchers found that the higher the level of concentration is the higher the level of profitability. In an earlier study I attempted to determine the level of concentration in the Turkish manufacturing industry for 84 sectors. In addition, I conducted a multiple regression analysis in various forms to identify the determinants of concentration and its effects on profitability. In most regression results, the relation between concentration and profitability was found positive and statistically significant. The present paper takes one step further and summarizes two new dimensions of industrial concentration. The first is to understand the current level of concentration for the Turkish manufacturing industry using a larger set of data. The new data set obtained from the TurkStat provides some basic statistics over the period 20092012 for 224 four-digit manufacturing industries. A brief analysis of the current data shows a slightly declining trend in the overall concentration ratio. CR4 (four-firm concentration ratio) fell from 51 to 49, CR8 (8-frim concentration ratio) fell from 61 to 60 , and $\mathrm{HHI}$ (or H for short, Herfindahl-Hirschman index) dropped from 0.173 (or from 1730) to 0.153 (or to 1530). However a much bigger drop is observed for a longer period in the data coming from the top 500 industrial firms of ICC (Istanbul Chamber of Commerce). The latter data show a sharp fall in CR8 from 32 percent to 24 percent. These results together reflect a falling tendency in the dominant role of large firms in the Turkish economy which is a sign of increased level of competitive environment.
\end{abstract}

Keywords: concentration, profitability, relationship, Turkish, industry

\section{Introduction}

The concept of industrial concentration refers to the control of a given industry (or market) by a small number of leading producers who are exclusively, or at least very largely, engaged in that industry. Why is concentration so important? Economic theory suggests that, with very few exceptions, any departure away from the competitive structure would lead to loss of efficiency. This conclusion is stated in the excess capacity theorem or under capacity utilization which is the main characteristic of imperfect market structure. Therefore it would not be misleading to argue that the higher the concentration is the greater the loss in general efficiency. Excluding two theoretically ideal market structure, namely perfect competition and monopoly, economists are left with oligopoly and monopolistic competition, as the actual market structure.

In 2014 the manufacturing industry in Turkey contributes about 18 percent to GDP at market prices among 20 broad categories of industries. Second and third highest shares accrue to trade and transport sectors each contributing about 13 percent respectively. Therefore a closer look at the structure and behavior of the firms in this branch of economic activities should challenge researchers.

The subject matter of this paper is to elaborate the possible causes and likely consequences of industrial concentration. The more emphasis is placed on the effects of industrial concentration on profit in the Turkish manufacturing industry. Accordingly, some hypothesis are tested using the data collected for the Turkish manufacturing industry. Within this framework three questions will be answered: 1 . What is the level of industrial concentration in the Turkish manufacturing industry? 2. What are the main determinants of the level of concentration? 3. What is the possible effects of industrial concentration on profit?

Knowledge of the structure of industry and its impact on the performance of the economy would be helpful not only from the theoretical standpoint but also for the purpose of policy formulation. In the event of possible integration with the European Union external considerations together with internal distributional issues require adequate knowledge relating to 
the functioning of economic forces and the performance of the producing units. These should be the main concern of the present and the future policy makers as Turkey has yet to develop anti-trust regulations to control monopolistic behavior and promote competition. However, the number of empirical investigations undertaken for the Turkish manufacturing industry within the structure-behavior-performance (SCP) framework are few. As such, the findings of the present study are likely to prove considerably helpful in many respects. Thereby special attention would be drawn for promoting further empirical investigations within the SCP framework not only in industry, but also in other main branches of the economy like trade, transport, and finance.

The remainder of this paper is organized as follows. In the next section I investigate the current level of concentration in the Turkish manufacturing industry. Following this, the main determinants of concentration is explained referring to an earlier research results. In the succeeding section the relationship between concentration and profitability is analyzed with the help of a simple set of regression models using the cross-section data for the year 2012. The final section concludes the paper.

\section{Level of concentration in the Turkish manufacturing industry}

In the literature various measures/indices of economic concentration are defined. Two most commonly used measures are concentration ratios, $\mathrm{CRi}$, (where $\mathrm{i}$ is an integer, like 4, 8, 20, and so on) and Hirchman- Herfindahl index, $\mathrm{H}$.

Concentration ratios are generally calculated for $i=4$ and $i=8$ as $C R 4$ and CR8. CR4 is the cumulative shares of the first four firms in the total output or the sales of firms operating in a specific industry. In statistical terms it is defined in the following formula

$$
C R 4=\frac{\sum_{i=1}^{4} S_{i}}{\sum_{i=1}^{N} S_{i}}
$$

where,

$\mathrm{Si}=$ the value of sales (or output) of an individual firm.

$\mathrm{N}=$ the total number of firms.

Similarly, CR 8 is defined as follows:

$$
C R 8=\frac{\sum_{i=1}^{8} S_{i}}{\sum_{i=1}^{N} S_{i}}
$$


In analyzing the structure of an industry the accepted critical levels of concentration for CR4 is 50 percent and for CR8 is 70 percent are accepted. That is if CR4 is above 50 percent and CR8 is above 70 percent the industry in question is considered as concentrated.

Herfindahl-Hirchman ( $\mathrm{H}$ for short) index is defined as the sum of the squared shares of all individual firms in an industry. It is calculated as follows

$$
H=\sum_{i=1}^{N} s_{i}^{2}
$$

Where

$s_{i}$ is the market share of firm $i$,

$N$ is the number of firms.

The Herfindahl Index $(H)$ ranges from $1 / N$ to one. If percents are used as whole numbers, as in 25 instead of 0.25 , the index can range up to $100^{2}$, or 10, 000 .

Three critical levels are defined using the $\mathrm{H}$ index as follows:

An $\mathrm{H}$ below $\quad 0 . \quad 1 \quad$ (or 1,000 ) indicates an unconcentrated index. An $\mathrm{H}$ between 0.1 to 0 . 18 (or 1,000 to 1,800 ) indicates moderate concentration. An $\mathrm{H}$ above 0.18 (or above 1,800 ) indicates high concentration.

A relatively small index either of the above indices (i. e. $\mathrm{CRi}$ or $\mathrm{H}$ ) indicates a competitive industry with no dominant players.

In one of the case studies carried out earlier by the author (Ozhan, 2000) it is found that in the Turkish manufacturing industry the average concentration is above the critical level. In particular CR4 with 1983 data was 58 percent and CR8 was 71 percent. After 14 years, in 2012 the same ratios fell to 49 percent and 60 percent respectively. Apparently, there is about 10 percentage points decrease in concentration ratios. Figure 1 shows these changes. 
Figure 1. Varying structure of industry, CR4 from 1998 to 2012

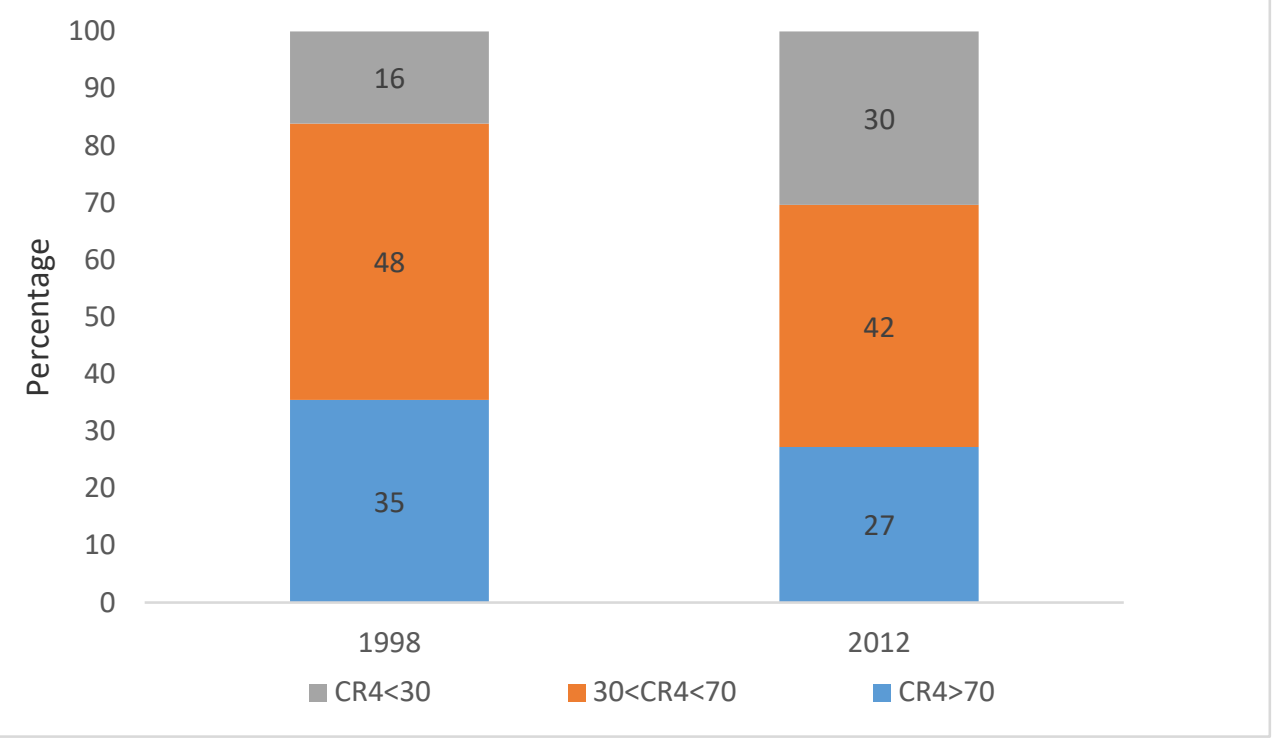

Source: Own calculations based on the data from TurkStat.

In figure 1, CR4 ratios are classified into three categories:

If $\mathrm{CR} 4$ is less than 30 the industry is unconcentrated.

If CR4 is less than 70 and greater than 30 the industry is moderately concentrated.

If CR4 is greater than 70 the industry is concentrated.

In order to understand the current structure of industry further $\mathrm{H}$ indices are calculated for 2012 . The results are presented in Table 1 below.

Table 1. Herfindahl-Hirshman index (H), 2012

\begin{tabular}{|l|l|l|}
\hline & Number of industries & $\%$ \\
\hline Unconcentrated (relatively competitive) industries $(\mathrm{H}<1000)$ & 125 & 61 \\
\hline Moderatelly concentrated industries $(1000<\mathrm{H}<1800)$ & 42 & 21 \\
\hline Highly concentrated industries $(1800<\mathrm{H})$ & 57 & 18 \\
\hline Total & 224 & 100 \\
\hline
\end{tabular}

Source: Own calculations based on the data from TurkStat.

Using the data from the TurkStat between 2009 and 2012 the it is seen that the $\mathrm{H}$ index has dropped from 0.173 (or from 1730) to 0.153 (or to 1530). Referring to this Table the $\mathrm{H}$ index for the Turkish manufacturing industries presents an unconcentrated structure.

Finally, using the $\mathrm{ICl}$ (Istanbul Chamber of Commerce) data covering the Turkey`s top 500 industrial enterprises a sharp drop is observed in the CR8. In 20 years from 1993 to 2012 the ratios fell from 32 percent to 24 percent. This historical record is given in Figure 2. 
Figure 2. Historical time trend of CR8, out of the largest 500 industrial firms



Source: Own calculations using the data from ICC (Istanbul Chamber of Commerce).

The ICC data shows a sharp fall in the CR8 from 1993 up to 1999 and it pikes up slightly from that point on in the following years.

These results together reflect a falling tendency in the dominant role of large firms in the Turkish economy which is a sign of increased level of competition.

\section{The determinants of industrial concentration}

Economists have identified six main factors that determine the level or the degree of concentration. These are scale economies, mergers and acquisitions, entry barriers, advertising, public policy, and stochastic variables. In the 1986 study of the author the main determinants of industrial concentration in the Turkish manufacturing industry the following explanatory variables are included in a set of multiple regression models|: economies of scale, absolute capital requirement, advertising intensity, growth rate of market demand, government credit availability, export and import. The model is tested employing the 1983 industrial survey data obtained from the TurkStat sources. Although the data made available by the TurkStat for all four digit industries (84 in number) some nonrandom samples of smaller sizes are also used. In the estimated equations all of the parameters appeared almost invariably with their expected signs - though with a low level of significance for some variables. These findings are presented in Table 2 for a double logarithmic model.

Table 2. Determinants of Concentration ratio

Dependent variable: InCR8

\begin{tabular}{|l|l|l|l|l|}
\hline & Coefficient & Std. Error & t Statistic & Prob. \\
\hline Constant & -1.3685 & 0.3273 & -4.1808 & 0.0000 \\
\hline
\end{tabular}




\begin{tabular}{|l|l|l|l|l|}
\hline $\operatorname{InSC}$ & 0.1756 & 0.0300 & 5.8549 & 0.0000 \\
\hline $\operatorname{InCLR}$ & 0.0948 & 0.0247 & 3.8311 & 0.0000 \\
\hline $\operatorname{InCR}$ & 0.1120 & 0.0474 & 2.3652 & 0.0030 \\
\hline $\operatorname{InAD}$ & 0.0985 & 0.0237 & 4.1615 & 0.0000 \\
\hline $\operatorname{InIM}$ & -0.0477 & 0.0218 & -2.1834 & 0.0030 \\
\hline InDE & -0.0210 & 0.0124 & -1.6949 & 0.0520 \\
\hline PPD & 0.1112 & 0.0941 & 1.1814 & 0.0630 \\
\hline R-squared & 0.7494 & & & \\
\hline Adj. R-squared & 0.7076 & & & \\
\hline F = & 17.9400 & & & \\
\hline Obser: & 50 & & & \\
\hline
\end{tabular}

Where

InSC: Measure of scale, average output of big firms in an industry

InCLR: Capital-labor ratio

InCR: Credit ratio

InAD: Advertising intensity

InIM: Import

InDE: Demand elasticity

PPD: Public or private dummy variable

In in this list expresses logarithm of variables.

In the model presented in the Table 1 all of the explanatory variables have their expected signs. The estimated coefficients have satisfactory statistical results reflected in relatively high $t$ values, as well as high $R$-squared and $F$ value. The use of the double logarithmic model is that the estimated regression coefficient for each explanatory variable measures the elasticity of the dependent variable with respect that variable (Gujaraty, Porter, 2010).

To conclude this section I can state that until a newer research result comes out the variables presented in the Table 2 should be relied on as the main determinant of industrial concentration. In addition to the SCP approach there are two more approaches trying to explain the degree of correlation between concentration and market power

\section{Effects of Concentration on Profitability}

Given the level and the determinants of economic concentration, a second important economic concern is how to predict the possible outcome of concentration. The traditional structure-conduct-performance (SCP) paradigm predicts that effective collusion between firms increases with industry concentration because concentration lowers the cost of collusion. In addition to the SPC approach there are two more approaches trying to explain the degree of correlation between concentration and the market power. These are known as the relative market power (RMP) hypothesis and the efficiencystructure (ES) hypothesis. 
The relative market power (RMP) hypothesis predicts a positive relationship between a firm's market share and its performance. That is, if consumers can rely on a firm's position in the market as an indicator of quality, this allows larger firms to earn supernormal profit. Therefore, the traditional SCP and RMP hypotheses provide an argument for antitrust regulation prohibiting actions that reduce the number of viable and potential competitors. However, an alternative view proposes the efficient-structure (ES) paradigm. According to this approach both the SCP and the RMP hypotheses ignore the possibility of market entry by new firms. From the standpoint of the ES paradigm, more efficient firms can charge lower prices than their competitors and still earn economic profits. Their comparative advantage allows more efficient firms to capture a larger market share in a specific industry, which will lead to an increase in market concentration. Thus, higher market concentration may benefit both firms and consumers; so that firms can earn higher profits while consumers can benefit from lower prices (Berry-S. -Weissb, S. , Wendee, S. , 2011).

Specifically, the SCP paradigm suggests some important relations. The most important of all is that the higher the level of concentration is the higher the level of profitability. Although there are no unanimous opinion on the direction of this relation most studies suggest a positive correlation between the level of concentration and profitability. In an earlier study (Ozhan, 1986) in order to investigate the relationship between concentration and profitability three different multiple regression models are tested. In these models a positive but statistically insignificant relationship is noticed between profitability (explained variable) and concentration (one of the explanatory variables). The profit variable in the TurkStat sources is not readily available. Therefore in my related studies I define profit by subtracting wages from the value added in each sector. So profit is defined indirectly in the form of nonwage income. The results of one these prior study is given in Table 3 below.

Table 3. Concentration ratio and profit relationship, 1983

Dependent variable: PRO

$\begin{array}{lllll} & \text { Coefficient } & \text { Std. Error } & \text { t- Statistic } & \text { Prob. } \\ \text { Constant } & 0.1630 & 0.0274 & 5.9483 & 0.0000 \\ \text { InCR4 } & 0.0997 & 0.0313 & 3.1844 & 0.0020 \\ \text { InCLR } & -0.0422 & 0.0122 & -3.4550 & 0.0000 \\ \text { PPD } & 0.1690 & 0.0471 & 3.5917 & 0.0000 \\ \text { R-squared } & 0.2560 & & & \\ \text { Adj. R-squared } & 0.2281 & & & \\ \text { F = } & 9.1800 & & & \\ \text { Obser }= & 84 & & & \end{array}$

In this table:

PRO: The ratio of profit (measured as nonwage income) to total sales.

InCR4: logarithm of 4-firm concentration ratio.

InCLR: logarithm of capital- output ratio.

PPD: Private/public dummy variable

Although the results of this semi-logarithmic model presented in Table 3 are statistically significant (due to high t-values) the model explains only about 23 percent of variation in profit ratio. The model captures the positive relationship between the level of concentration and profitability. 
In the same model the negative sign of capital-labor ratio implies that as capital intensity increases, the share of profit in value added falls. This negative relationship can be attributed to the diminishing marginal productivity as capital per labor increases.

To test the relationship between profit and concentration with the new set of data I tried three linear regression models. In the first model I selected a set of industries ( $n=99$ out of 224 four-digit industries) for 2009 with a profit rate of less than 10 percent. The scatter chart

of the data in this sample is given in Figure 3 .

Figure 3. 4-Firm Concentration Ration (CR4) and Profit Rate, 2009

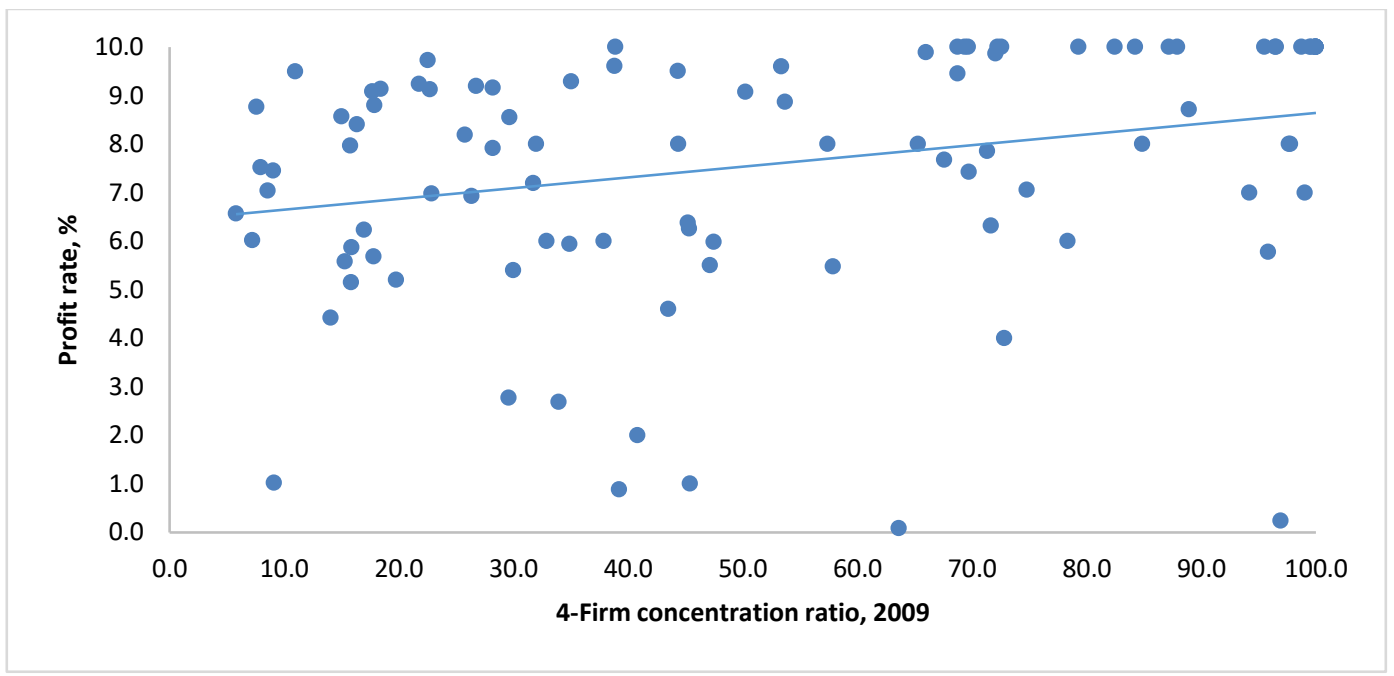

The chart reveals that a slight positive relation does exist between profit ratio and four firm concentration ratio (CR4). This is show in a dark line with a positive slope in the same figure.

For the same set of data the results of a simple two-variable linear regression model are given in Table 4 .

Table 4. CR4 and Profit rate for industries with profit rate less than 10 percent

\section{SUMMARY OUTPUT (Model 1)}

Dependent variable: PRO

Regression Statistics

$\begin{array}{ll}\text { Multiple R } & 0.274382 \\ \text { R Square } & 0.075285 \\ \text { Adjusted R Square } & 0.065752 \\ \text { Standard Error } & 2.420936\end{array}$

Observations

51.5

7. 6

0.150712 
ANOVA

$\begin{array}{llllll} & d f & S S & M S & F & \text { Significance } F \\ \text { Regression } & 1 & 46.2851 & 46.2851 & 7.897229 & 0.00599 \\ \text { Residual } & 97 & 568.5102 & 5.860929 & & \\ \text { Total } & 98 & 614.7953 & & & \end{array}$

Coefficients Std Error t Stat P-value

$\begin{array}{lllll}\text { Intercept } & 6.429023 & 0.473305 & 13.58327 & 3.59 \mathrm{E}-24 \\ \text { CR4 } & 0.022152 & 0.007883 & 2.810201 & 0.00599\end{array}$

The regression results support hypothesis stating the positive correlation between concentration and profitability. However the model explains only a small portion (about 7 percent) of the variation in profitability is explained by CR4. From the same regression results it is also possible to calculate that the elasticity coefficient of midpoint is 0.1507 . That is to say that a one percent increase in CR4 leads to 0.1507 percent increase in the profit rate.

The second regression model is also estimated with a larger set of data covering 193 sectors for 2012. The scatter chart of the second model is depicted in Figure 4.

Figure 4. Profit rate and CR4 for 193 industries in year 2012

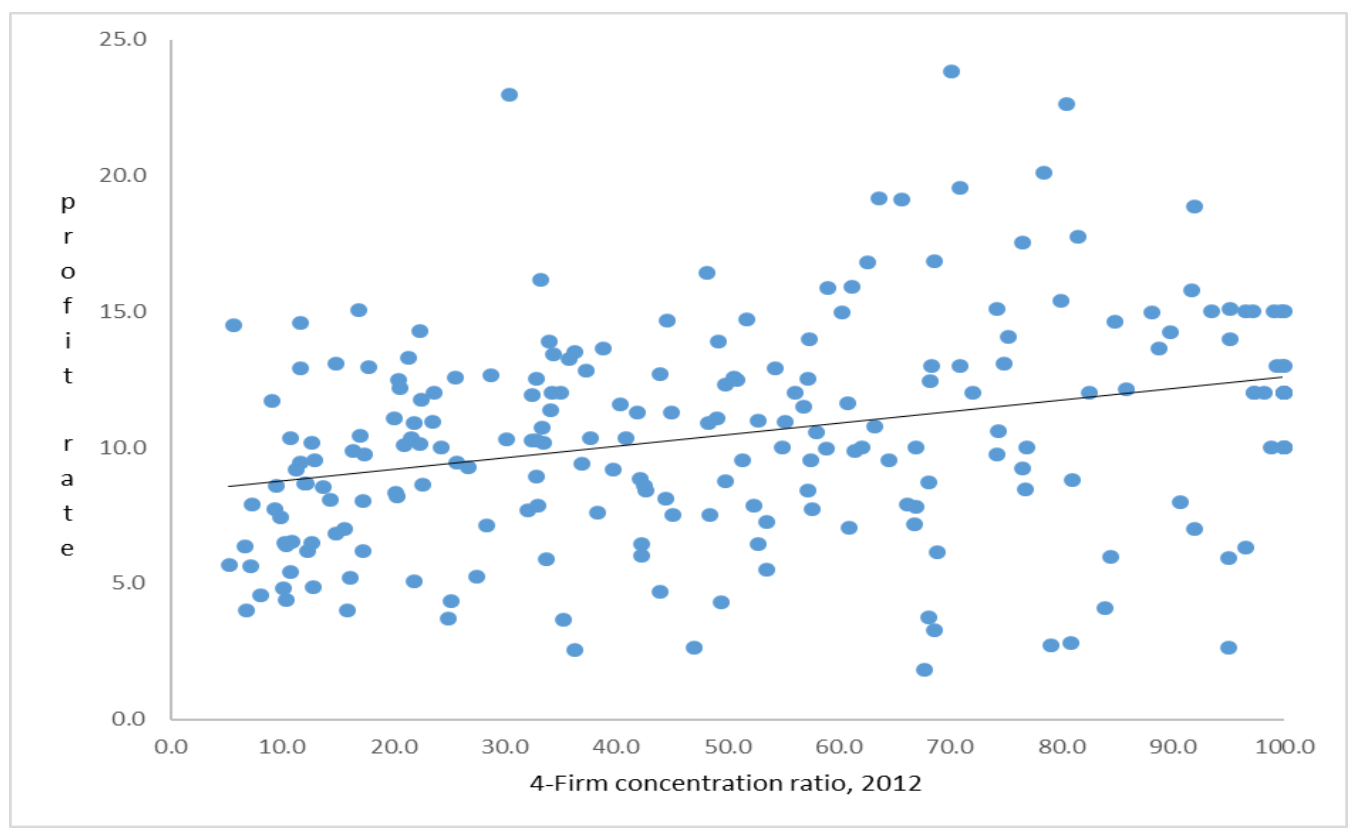

The regression results are given in Table 5 . 
Table 5. Regression results for profit rate for 193 industries in year 2012

SUMMARY OUTPUT (Model 2)

Dependent variable: PRO

Regression Statistics

Multiple R

0.315954

R Square

0.099827

Adjusted R Square

0.095114

Standard Error

3. 24761

Observations

193

ANOVA

$\begin{array}{llll} & d f & S S & M S \\ \text { Regression } & 1 & 223.3998 & 223.3998 \\ \text { Residual } & 191 & 2014.472 & 10.54697 \\ \text { Total } & 192 & 2237.872 & \end{array}$

$F$

21. 18141

Significance $F$

7. $6 \mathrm{E}-06$

Coefficients Std Error t Stat P-value

$\begin{array}{lllll}\text { Intercept } & 9.41701 & 0.476021 & 19.78277 & 4.07 \mathrm{E}-48 \\ \text { CR4 } & 0.037551 & 0.008159 & 4.602327 & 7.6 \mathrm{E}-06\end{array}$

In the second model with increase number of observations the adjusted $R^{2}$ is slightly increased to about 10 percent and the t value for CR4 is also increased from 2. 8 to 4 . 6 . The mean of CR8 is 49.5 percent and the mean of profitability is 11.3 percent. Accordingly, the elasticity of profitability at the midpoint is 0.1645 . It means that as the 8 - firm concentration ratio increases by one percent around its mean profitability ratio increases by 0.165 percent.

Finally, a third model is constructed for the relationship between CR8 and profitability with 195 data points (sectors). The scatter chart of the model is given in Figure 5. 
Figure 5. Scatter chart for CR8 and profit rate 2012 for 194 industries

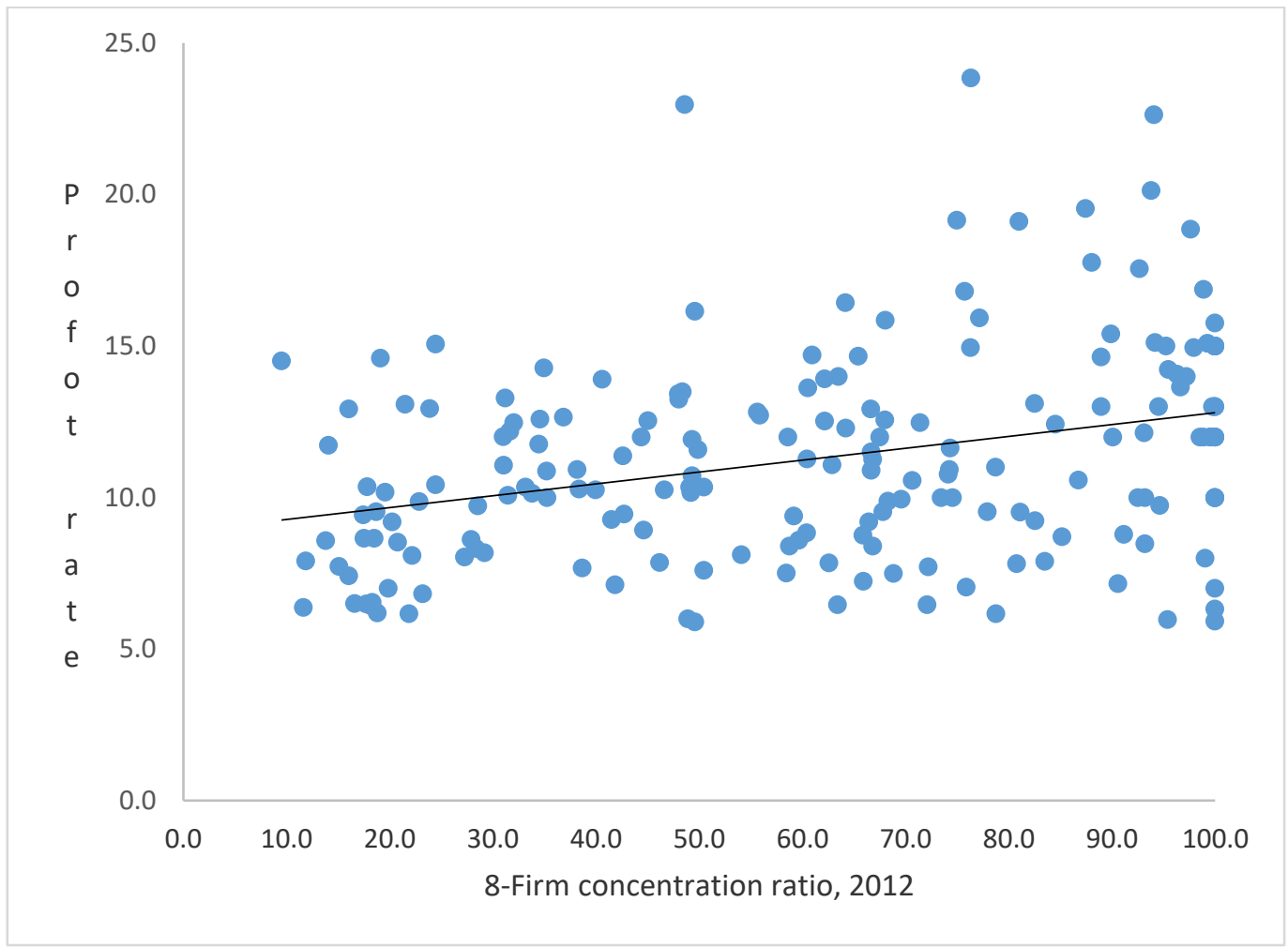

The results of the third regression model are given in Table 6 .

Table 6. Regression results for CR8 and profit rate 2012 for 194 industries

SUMMARY OUTPUT (Model 3)

Regression Statistics

Multiple R

0.32496

R Square

0.105599

Adjusted R square

0.100941

Standard Error

3. 249804

Observations 
ANOVA

$\begin{array}{llllll} & d f & S S & M S & F & \text { Signif } F \\ \text { Regression } & 1 & 239.4106 & 239.4106 & 22.66884 & 3.78 \mathrm{E}-06 \\ \text { Residual } & 192 & 2027.755 & 10.56122 & & \\ \text { Total } & 193 & 2267.165 & & & \end{array}$

Coefficients Std Error $t$ Stat P-value

$\begin{array}{lllll}\text { Intercept } & 8.884798 & 0.557874 & 15.92618 & 5.95 \mathrm{E}-37 \\ \text { CR8 } & 0.039149 & 0.008222 & 4.76118 & 3.78 \mathrm{E}-06\end{array}$

Although the $\mathrm{R}^{2}$ is still relatively (about . 10) it is the highest among the last three models. Briefly, the model shows that about 10 percent of the variations in the mean value of profitability is expressed by the variations in CR8. The remaining 90 percent variations are attributed to other variable which are not included in the model. Finally, the mean of CR8 is 61.6 percent and the mean of profit rate is 11.3 percent. So the elasticity for the 8-firm concentration ratio at the average of both variables is 0.214 . This figure shows that as CR8 increases by one percent the profit rate in that industry increases by 0.214 percent.

\section{Conclusion}

Using the TurkStat data for the 224 four-digit manufacturing industries it has been observed that that there is a slightly decreasing trend in the overall level of concentration. This result is also supported by looking at the data collected from the Turkey's top 500 industrial enterprises by the Istanbul Chamber of Commerce. Both of these statistics indicate a falling tendency in the dominant role of large firms in the Turkish economy which is a sign of increased level of competition.

Economists accept that concentration disturbs social welfare, because in concentrated industries the profit margin of firms is relatively higher than unconcentrated industries. In the related literature many researchers adhering to the SCP approach found a positive relationship between concentration and profitability. In the Turkish manufacturing industries there is a falling tendency of overall concentration from 2009 to 2012. However about 100 industries (40 percent) out of 224 industries CR4 is above the critical level of 50 percent. This study also shows that there is a positive and statistically significant relationship between concentration and profitability.

The reasons for this high level of concentration is common to most developing countries. At the beginning of industrialization process governments encourage big size firms and do not regulate markets by anti-trust policies. In Turkey antitrust law is put into force in 1994. On the other hand because of indivisibility and the small size of the domestic market, the firms are born in an uncompetitive environment. For most of the industries the minimum efficient scale (MES), is the natural explanation of this structure. But, the concentration above this technically required level is not acceptable for economic and social reasons. Still there is a need for further study to provide more comprehensive results in the field. In the light of new research the government can apply antitrust policy vigilantly.

\section{References}

[1] Blair, J. M. (1972) Economic Concentration: Structure, Behavior and Public Policy. Harcourt Brace Jovanovich Inc.

[2] Gujaraty, D. N. , Porter, D. C. (2009) Basic Econometrics, 5/E.

[3] ICC (Istanbul Chamber of Commerce) (2015), The 500 Largest Industrial Firms. 
[4] Martin, S. (2010) Industrial Concentration in Context, OUP.

[5] Ozhan, M. (2001) Concentration in the Turkish manufacturing Industry (Istanbul, conference presentation?).

[6] -------, (1986) "Türk İmalat Sanayinde Yoğunlaşma" Asomedya, Ankara.

[7] -------, 1989, "Karlılık, Verimlilik ve Yoğunlaşma Illişkisi" Verimlilik Dergisi, MPM, Ankara.

[8] -------, 1990, "Avrupa Sanayi Yapısı ve Türk İmalat Sanayi" Kalkınma Bankası Dergisi, Ankara.

[9] Thomas R. Berry-Stölzlea, Mary A. Weissb, Sabine Wendec, (2011) Market Structure, Efficiency, and Performance in the European Property-Liability Insurance Industry.

[10] TurkStat: www. tuik. gov. tr

[11] Waldman, D. E. and Jensen, E. J. 2014, Industrial Organization, Addison Wesley. 